\title{
Midwifery to be offered in Newfoundland and Labrador
}

$\mathrm{N}$ ewfoundland and Labrador will offer midwifery services within five to seven years, leaving only two Canadian jurisdictions without: Prince Edward Island and the Yukon.

The Minister of Health and Community Services of Newfoundland and Labrador, Susan Sullivan, gave the green light for a province-wide rollout following the release of a report that explored the benefits of midwifery and outlined a plan for implementation.

According to the report, Implementing Midwifery in Newfoundland and Labrador, midwifery will help the province address two major concerns: cesarean deliveries and breastfeeding. The province has the highest rates of the former and the lowest rates of the latter in Canada. On average, $31 \%$ of women in the province deliver by cesarean; nationally the rate is $27 \%$. In addition, $59 \%$ of new mothers breastfeed compared with $90 \%$ nationally.

Midwives, who monitor and assist women through pregnancy, labour and the postpartum period, provide education about the importance of breastfeeding and have been shown to reduce the need for medical interventions like cesarean delivery.

Making midwifery a reality, however, will take more than acknowledging its benefits.

"As a government, we need to achieve a sustainable balance between patient care and choice, public protections and appropriately planned implementation in the health care system," Sullivan told $C M A J$ in an email.

The province is establishing regulations for the practice of midwifery under the Health Professions Act, and appointing an implementation coordi-

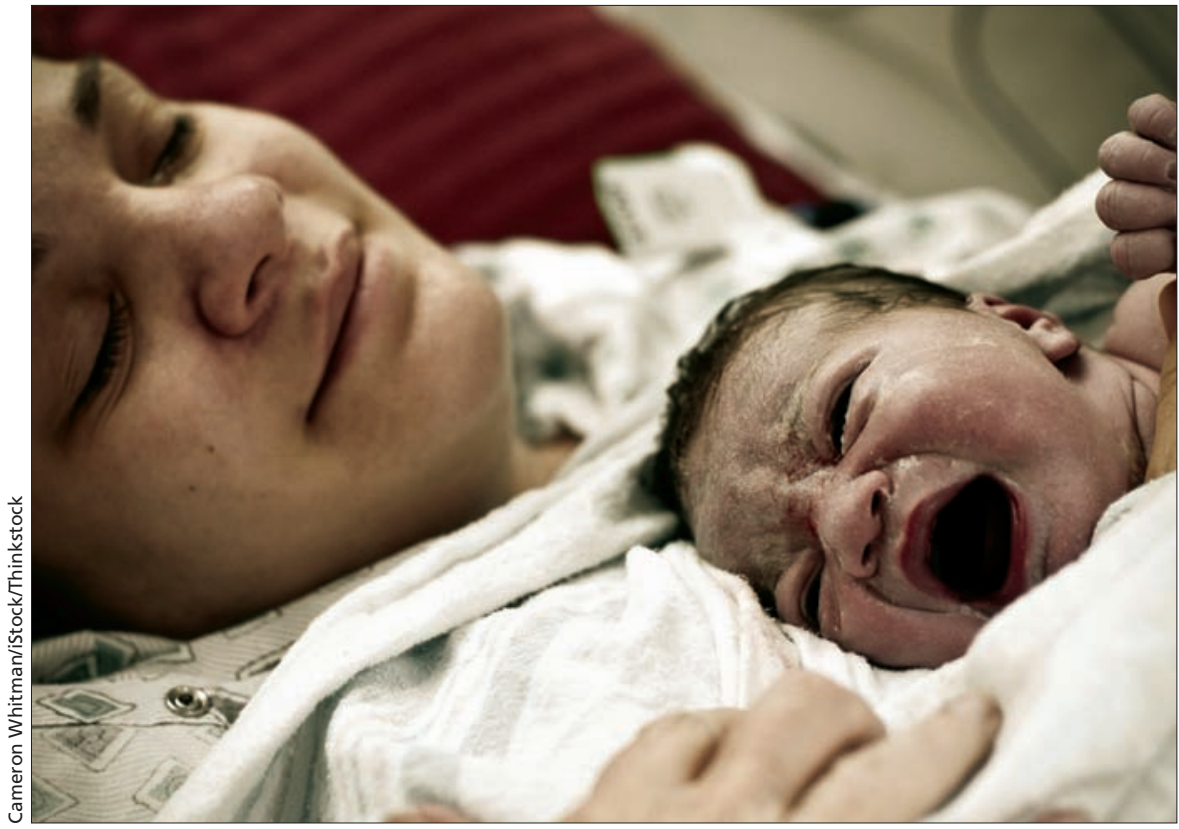

Experts say that midwifery will help reduce high rates of cesarean deliveries and increase low rates of breastfeeding in the province.

nator and advisory committee. The provincial government will also work with the Newfoundland and Labrador Council of Health Professionals and the Association of Midwives of Newfoundland and Labrador to establish a transitional college, which will work with other professions to develop regulations, says Sullivan.

The Newfoundland and Labrador Medical Association, which was not consulted for the report, does not yet have a position on the midwifery announcement. "We will bring this before the board," says Jonathan Carpenter, the association's director of communications and public affairs.

Successful implementation of midwifery will require collaborative practices, says Dr. Don Wescott, an obstetrician in Antigonish, Nova Scotia, where midwifery is well established. In Wescott's collaborative practice, all patients are seen by a doctor and midwife. "It should not be an adversarial or competitive process," he says.

The Canadian Association of Midwives applauds the Newfoundland and Labrador government for commissioning the report and embracing its recommendations. There is one bone of contention, however. Initially, people will have to pay for midwifery services, either out-ofpocket or through insurance.

"This will create a two-tiered system," says Joanna Nemrava, the association's president. "How will midwives be part of a collaborative health care team if they operate under a different model?" — donalee Moulton, Halifax, NS

CMAJ 2014. DOI:10.1503/cmaj.109-4767 